\title{
New Design for Life Jackets using Smart Plastic
}

\author{
Xiangyun HUANG \\ North China Electric Power University, China
}

\begin{abstract}
With the rapid development of modern society, a series of social problems in population, resources, environment, public health and other aspects get acute increasingly. When major natural disasters, safety incidents and unexpected public health events occur, goods transport efficiency will directly affect the disaster rescue of emergency or sudden public events. Based on the current widespread use of the incompressible polyethylene foam jacket of big size [1], we adopt this new type of shape memory polyurethane material [2] to replace the original filler material of the jacket, greatly decreasing the transport and storage resources of life vest. And it can be triggered by electric heating plate quickly and be put into use efficiently .The most remarkable thing is, however, the new material of our life vest can be recycled after using. In the whole process, transport and storage resources waste is greatly reduced, and the utilization rate of the material is largely improved.
\end{abstract}

KEYWORDS: smart plastic; life jackets; shape memory polyurethane; recyclable and compressible, electrictriggered.

\section{BACKGROUND}

Our country is rich in water resource and serious floods together with water accident happened frequently in recent years. Life jacket is a must in rescue and emergency operations. As the necessary personal protective equipment, it plays a vital role in ensuring the safety of rescue workers. Currently, the polyethylene foam padding jackets are widely used in the flood relief, which is of light quality, large buoyancy [3] and low price. But the biggest drawback of foam is its big volume and small shrinkage, which takes up a lot of space in transportation, therefore wastes a great deal of manpower and financial resources, seriously affects the efficiency of a disaster relief.

Especially in the case of roads being damaged, transport resources get more and more precious. But the polyethylene foam jackets a truck can carry is much lower than its maximum load. Thus great waste are caused, moreover, that will even lead to the delay of best rescue time, which means immeasurable loss.

\section{DESIGN INSPIRATION}

Therefore, we hope to design a new type of life jacket equipment, and looking for a kind of material whose original size is small. But when under certain conditions, it can be triggered easily and inflate rapidly. And the inflation is not easy to be damaged. Obviously, this kind of lightweight materials of characteristics above is very suitable to be the filler of life jackets. Considering the material properties, we choose the right means of trigger by some related calculation. Then we design a set of complete new portable life jackets and equipment. Such a design decreases the waste of the storage and transport resources greatly. And when you need to use, it can be quickly trigger and put into use. All in all, the new design not only improves the practicality of the life jacket but also improves the efficiency of disaster relief and large-scale military activities, which won our new product a broad prospect of application.

\section{MATERIAL SELECTION}

First of all, we need to find a new material with the characteristics of light quality, rapid expansion when triggered, damage failure free in the harsh environment. Here we choose the smart plastic made of shape memory polyurethane. As long as the heating power supply connected, the plastic can be 
like popcorn, expand into any shape you want. If you are dissatisfied with current situation, you can also give it a shape again through software. If the final product is damaged, it' $\mathrm{s}$ able to be melted and form new objects in a few minutes. Damage will be automatically healed in the same time [4].

\section{THE PERFORMANCE PARAMETERS}

The ideal thermal transition temperature for our shape memory polyurethane material is during 75$90{ }^{\circ} \mathrm{C}$. For the expanded shape memory polyurethane, when heated to its thermal transition temperature more than 10 seconds, you can put external force to compressed it into any shape we hope to get [5]. Then cool the material dawn, stress has been "frozen" within the material and the shape memory polyurethane has been compressed into the shape we want. In the same way, when heated to the thermal transition temperature once more, the internal stress within the material will be released once again, material can swell in a short time. When need to get recovery, just heat again to thermal transition temperature [6], apply force to remodel material, and then cool it. This is the recycling process of the material. The most ideal inflation rate is as high as $400 \%$, the relative density of the expanded material is $0.275--0.3$, suitable for making life jacket of filling materials. The shaping process [7] of smart plastic is shown in figure 1.

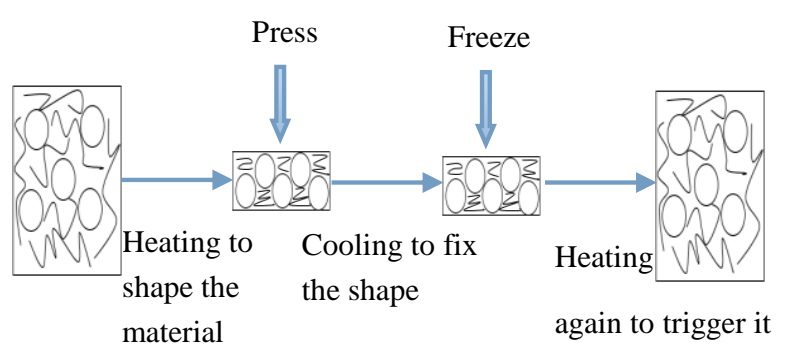

$$
\text { - } \text { Stationary phase } \checkmark-\text { Reversible phase }
$$

Figure 1. The shaping process of smart plastic

\section{OVERALL DESIGN}

We have eight capsules of life jackets to put the filling materials. In order to guarantee the comfort and stability, we design four capsules in front of the jacket and the same capsules behind it respectively, and all of them are symmetrical. Each capsule is filled with the new type of material, shape memory polyurethane. And all capsules are connected to the electric initiating device. The electric initiating device is connected to the power socket by wires, which is triggered by the power socket of the power converter. The power supply is made up of $35 \mathrm{~V}$ direct current regulated power supply transformed from $220 \mathrm{~V} / 50 \mathrm{~Hz}$ alternating current.

Electrical initiating device stimulus the shape memory polyurethane in the form of electric shock, making the filling materials expand to meet the size of the preset capsule. When all capsules are filled with the rapid expansion of the shape memory polyurethane, it's time for it to create buoyancy and be put into use. The overall design is shown in figure 2 of two perspectives.

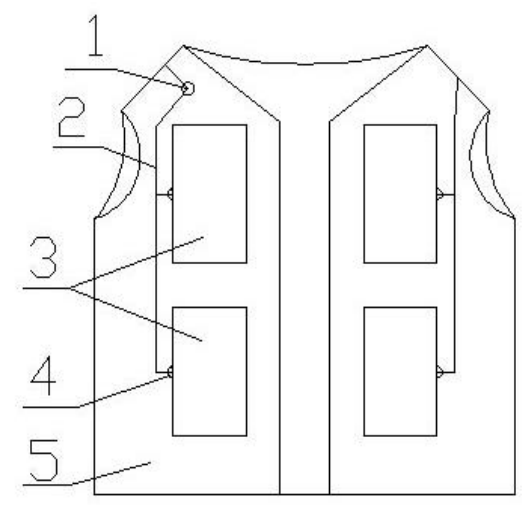

Figure 2. (a) The front view of life jacket

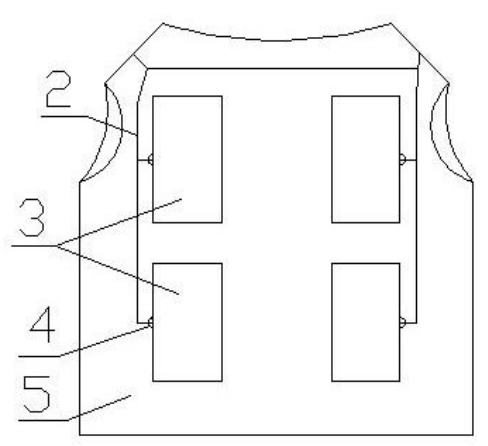

Figure 2. (b) The back view of life jacket

In figure 2, 1 power socket, 2 wires, 3 capsule, 4 electric ignition device, 5 life jackets ontology.

\section{THE FLOW CHART OF USING DIRECTIONS}

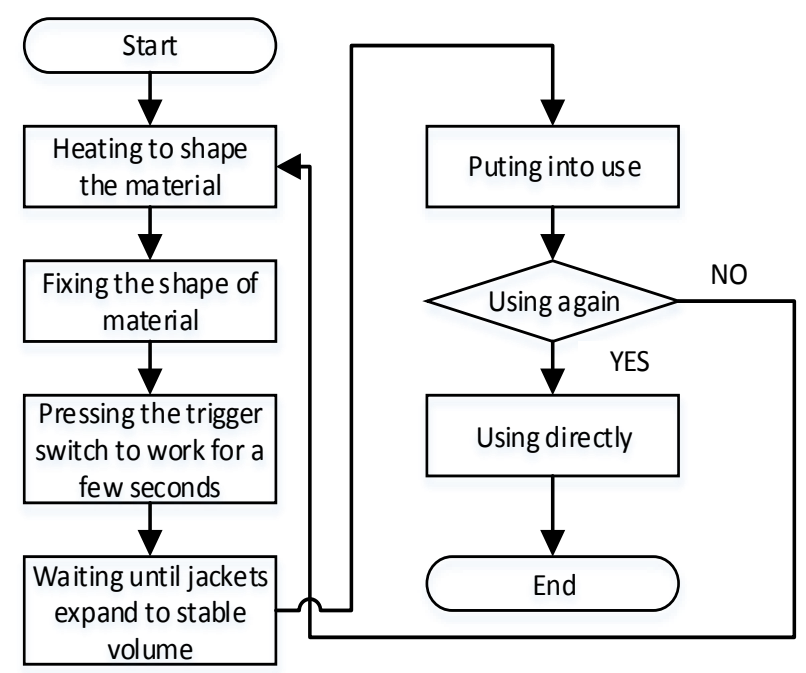

Figure 3. The using directions 


\section{CONCLUSIONS}

Based on the fact that existing life-saving equipment's big volume and small shrinkage, which becomes a waste of the transport resources. Based on the above reasons, we adopted the shape memory polyurethane smart plastic as a substitute for existing life-saving device implants, and get it into rapid expansion in a short time through electrical heating and then we put the expanded life jackets into use. Our new design makes life vest more portable and user-friendly, while it is still safety and of high comfort,which not only reduces the transport and storage resources waste and improves the utilization rate of the material in a large degree, but also win a great application prospect in flood disaster relief, emergency water accident treatment and large-scale military activities.

\section{ACKNOWLEDGEMENTS}

This work has been supported by the Fundamental R esearch Funds for the Central Universities (12MS14
2, 13ZD23, 2014MS162) and College Students' Inno vation Project (20142254).

\section{REFERENCES}

[1] Gu Ping, Dai Xuemei The design and calculation of high buoyancy bathing suit packing materials, 2009.

[2] Yan Bing Study on the structure and properties of shape memory polyurethane - polyurethane industry, 2003 (03).

[3] XiaoGong. Jackets buoyancy and new buoyancy materials research. Beijing: Beijing institute of fashion technology, 2003.

[4] Xin-qiang gao Intelligent plastic that can automatically repair damaged.

[5] Ya-dong Chen, Peng Zhenbo, Zhang Huibo, Laifu LiHeat The research and application of shape memory polyurethane materials, 2010.

[6] The performance of shape memory polyurethane research and application, LiShu-cai, Li xin, 2013.

[7] Shao-jun Chen wen-bin Zhao peng-sheng Liu Silane Silane coupling nano SiO2 modified shape memory polyurethane, 2005. 